\title{
Visualization analysis of the studies on reading perceptual span in China
}

\author{
Guiyun Guan ${ }^{1, a}$, Hewei Zhang ${ }^{2, b}$, Axu Hu ${ }^{1, c}$, Hongzhi Yu,d, \\ ${ }^{1}$ Northwest Minzu University, Gansu, Lanzhou, China \\ ${ }^{2}$ Lanzhou University, Gansu, Lanzhou, China

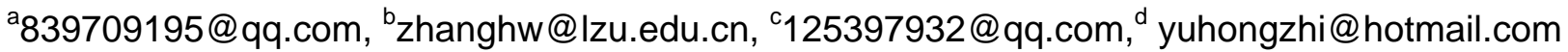 \\ ${ }^{*}$ Corresponding author
}

Keywords: perceptual span; visualization analysis, knowledge map

\begin{abstract}
Perceptual span, as one of the most fundamental problems in the reading research, has attracted many researchers' attention. The paper makes use of Citespace III and the visualization analysis on CNKI to make an analysis of reading perceptual span in China from 1998 to 2008, so that it can make the current research states clear and provide guidance for the future study on the subject.
\end{abstract}

\section{Introduction}

Perceptual span means the range of the useful information that a reader gets from one-time fixation in the process of reading, that is, the range of the information on the left and right sides of the fixation point, or the range of the perceptually processed reading material. Perceptual span is one of the fundamental problems in the research of reading, as well as an issue with great practical significance. (McConkie and Rayner, 1975; L.H.Wang, X.J.Bai and G.L.Yan, 2014) Perceptual span can reflect a reader's efficiency of reading and strategies of reading processing (G.L.Yan, J.P.Xiong and X.J.Bai, 2008)

The research of reading perceptual span abroad started early. In 1908, Huey put forward the concept of perceptual span. Then researchers made use of speed method, original window technology, and mean method to do research on reading perceptual span, but till 1975 McConkie and Keith Rayner used moving window paradigm of eye-movement contingent display changes technique to study reading perceptual span, which provided a completely new method for the research of reading perceptual span and pushed the research forward. In 1976, McConkie and Rayner found the left-right asymmetry of reading perceptual span. From then on, more and more studies have been carried out on reading perceptual span.

But in China, the study on reading perceptual span fall behind western countries. On CNKI, put in perceptual span as the key word, CSSCI, EI, SCI, CSCD, Core Journals as the main sources, 1998-2008 as the period to go on advanced search, and 38 records appear(Fig.1.) by Oct 10 2018. In order to guarantee the accuracy of the research, all of the records are verified item by item and they are all related to perceptual span. It is obvious on figure 1 that the first paper about perceptual span was published in 2003. From 2007 the publication became rise, and peaked in 2013. The trend is correspondent with the actuality: reading perceptual span is one part of eye movement research, but in China it started very late because of the high price of eye trackers; there are not many researchers in the field. But under the influence of western researchers, more and more research are done in the field. 


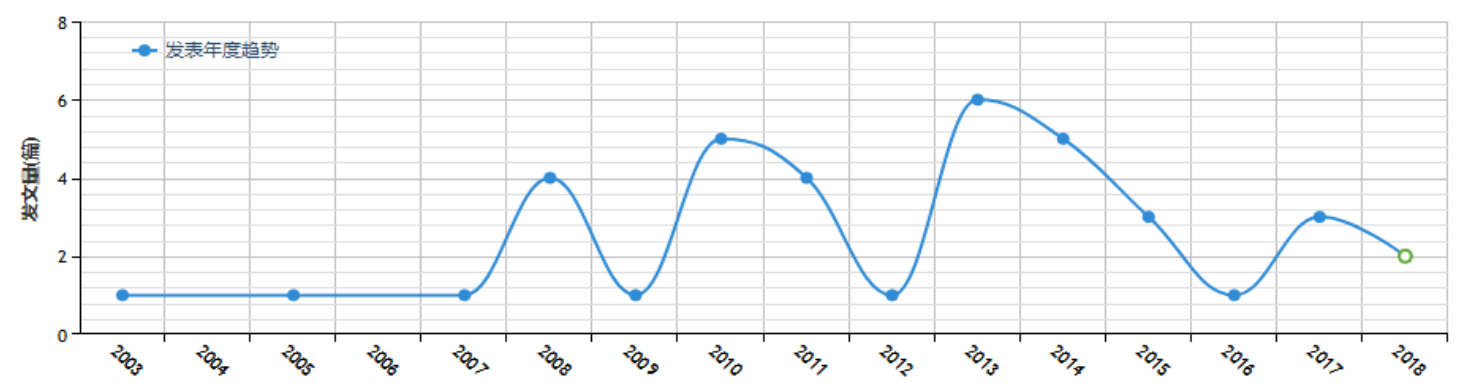

Fig. 1. Tendency chart of the paper publication about perceptual span from 1998 to 2018

On CNKI, put in perceptual span as the key word and go on advance search in the sources of CDMD (Doctor/Master Dissertations Full-text Database) from 1998 to 2018. 33 records came out. In order to guarantee the accuracy, the records are verified item by item. 12 dissertations are relevant (Fig.2.). The first master dissertation was finished by Xiong Jianping in 2007, titled "Eye Movements and the Perceptual Span of Different grades in Chinese Reading”.

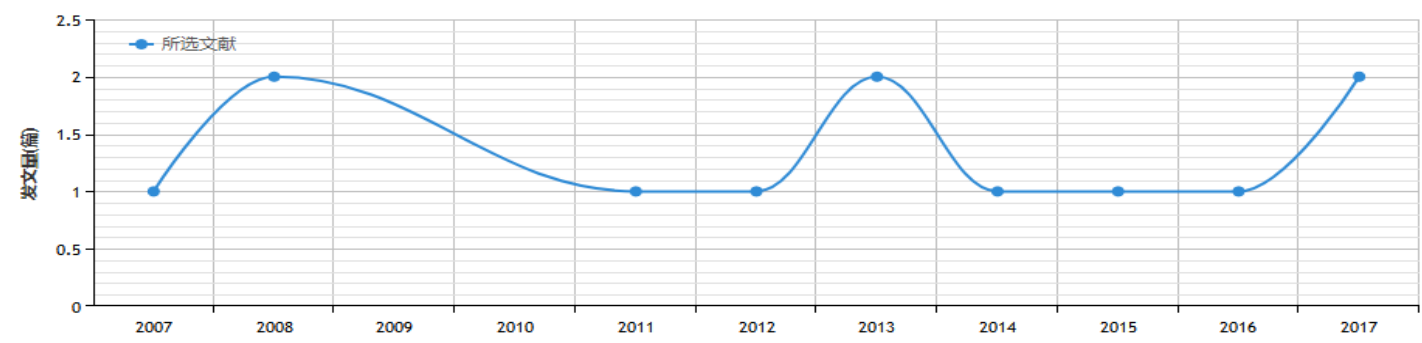

Fig. 2. Tendency Chart of the dissertations about perceptual span from 1998-2018

\section{The Status Quo of perceptual span in China}

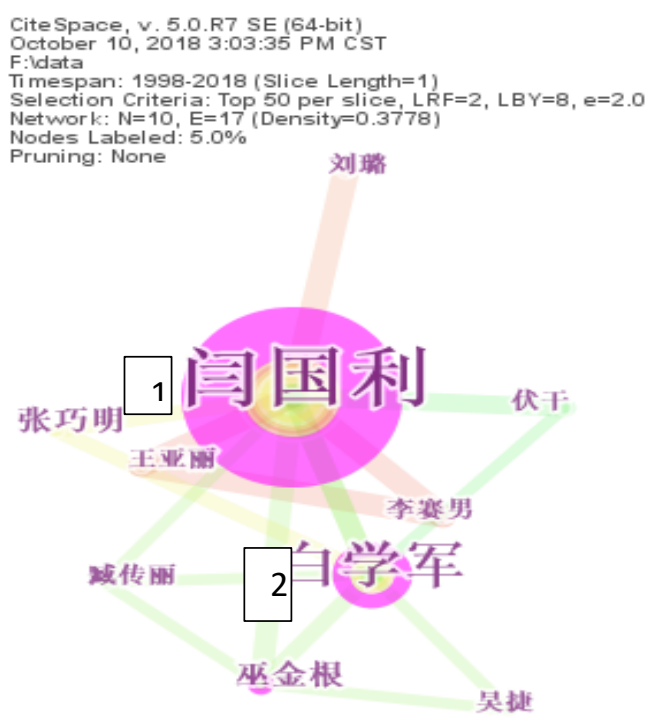

Fig.3. Authors' cooperative relationship

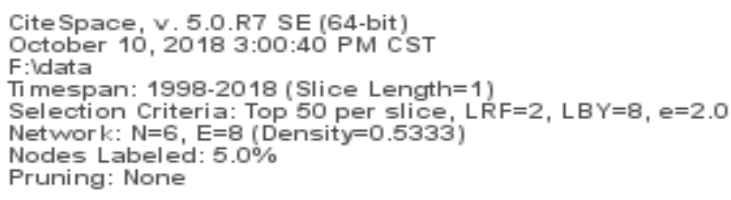

星理随眼动变化技术

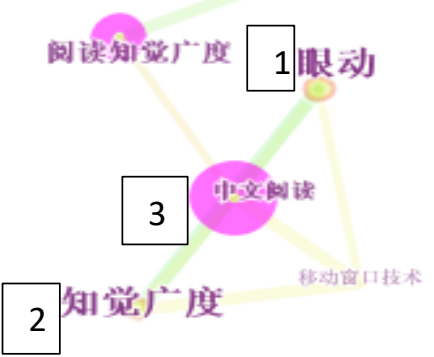

Fig. 4. Key words in the papers

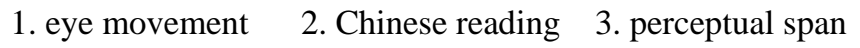

In China, the earliest paper titled " The research theory and practical thoughts on middle school students' fast reading” written by Han Yinghong and Yan Guoli was published in Psychological Science in 2003. The paper questioned the method of improving students' reading speed by enlarging perceptual span, because the perceptual span was limited. Later, many researchers began focus on perceptual span. Till 2008, great breakthrough was made: four papers were published in the year; the research methods and processed had great innovation. Then researchers did further research on perceptual span.

The study, using Citespace III to analyze the 38 records and setting author as the search term, 
finds that Yan Guoli and Bai Xuejun are the leaders in the field of perceptual span. In China, there are not many researchers in the field (Fig. 3.) and other authors, such as Zang Chuanli, Fu Gan, Wu Jingen, Wang Yali, and so on all have more or less cooperative relationship with Yan Guoli and Bai Xuejun. This phenomenon is similar to that in western countries: Keith Rayner, McConkie and Inhoff are the leaders in the field in western countries and many other researchers cooperate with them.

In Fig. 4., perceptual span is set as the search term and readers can find that researchers takes advantage of moving window paradigm in eye-movement contingent display changes technique to study the readers' reading perceptual span, especially in Chinese reading.

In Fig. 5., institute is set as the search term and Academy of Psychology and Behavior in Tianjin Normal University is found the institution with the most research results. Guoli Yan, Xuejun Bai and many other authors work or study in the academy. It proves that there are not many researchers in the field, and more researchers are needed.

\begin{tabular}{|c|c|c|c|c|c|c|}
\hline BurstCentralitySigmaP & Rankk & Author & YearTitlesourceV & Vol Pag & iffec & \\
\hline \begin{tabular}{l|l|l|} 
& 0.33 & 1.00 \\
\end{tabular} & 0.00 & 天建师范大学儿理与行为研究浣 & $2008 \ldots . . .50$ & $V P$ & 3 & \\
\hline $0.00 \quad 1.00$ & 0.00 & 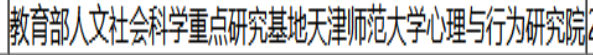 & $2017 \ldots . . .50$ & $V P$ & 0 & \\
\hline 0.001 .00 & 0.00 & 鲁东大学期育科学学完 & $2013 \ldots . . .50$ & $V p$ & d & \\
\hline 0.0001 .00 & 0.00 & 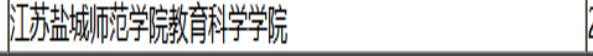 & $2000 \ldots$ & $V P$ & 0 & \\
\hline 0.001 .00 & 0.00 & 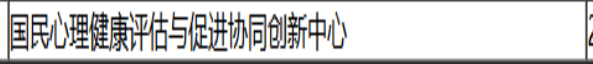 & $2017 \ldots . .150$ & V P & 0 & \\
\hline
\end{tabular}

Fig. 5. Paper publishing Research Institutes

1. Academy of Psychology and Behavior, Tianjin Normal University

2. Key research base of Humanities and social sciences of the Ministry of Education,Academy of Psychology and Behavior, Tianjin Normal University.

3. School of Educational Science, Ludong University

4. School of Educational Science, Yancheng Teachers University

In Fig. 6., Academy of Psychology and Behavior, Tianjin Normal University is the institute with most dissertations related to perceptual span, which is the same as paper publishing institution. Xinjiang Normal University and Northwest Minzu University contribute one dissertation respectively.

机构分布

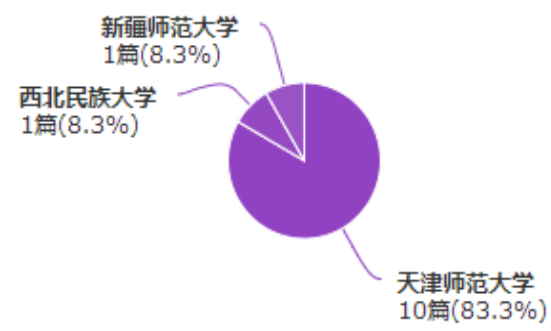

Fig. 6. Master/ Doctor Dissertations publishing Institutes

\section{Main Research Directions in Perceptual Span in China}

From the visualization analysis on CNKI (Fig. 7.), we can see more exact information about the themes in all the related papers: reading perceptual span occupies 14.72 percent, fixation point 9.82 percent, perceptual span, 9.3 percent, eye movement 7.36 percent. Besides, reading speed, asymmetry, Chinese reading are also important themes.

The followings are main research directions

\subsection{Perceptual span in Chinese reading}

The study on Chinese reading in western countries began in 1980s (Peng, 1983; Sun, 1985) and drew the conclusion that Chinese reading was generally similar to English reading in eye 
movements. Some people (Inhoff \& Liu, 1998) did experiments on Chinese reading perceptual span of Chinese students studying abroad with the help of moving window paradigm, proving the left-right asymmetry of Chinese reading perceptual span. But in China, till the beginning of the century, researchers began to study perceptual span in Chinese reading. Xiong Jianping studied the perceptual span and eye movements in Chinese senior high school readers in 2007, finding that their perceptual span is about 1 to 2 characters of space on the left and 3 to 4 characters of space on the right side of the fixation point. (J.P.Xiong, 2007) Yan Guoli, Xiong Jianping did experiments on the perceptual span of Chinese reading by fifth grades, finding that their perceptual span is about 1 character on the left and 2 to 3 characters of space on the right side of the fixation point.(G.L.Yan, J.P.Xiong and X.J.Bai, 2008) All of these proved the left-right asymmetry of perceptual span. Some people did experiments on perceptual span of reading Chinese materials of different degrees of difficulty, drawing a conclusion that perceptual span of reading easy materials was 5 characters, while perceptual span of reading difficult materials was 3 to 5 characters.(G.L.Yan, G.Fu and X.J.Bai, 2008) The distribution of concentration and reading direction decided the asymmetry of perceptual span. (G.L.Yan, J.G.Wu, Y.W.Hu and X.J.Bai, 2010) Some people studied the influence of font size on the perceptual span in Chinese reading, finding that font size affected the concrete eye movements but not perceptual span. (J.G.Wu, 2014)
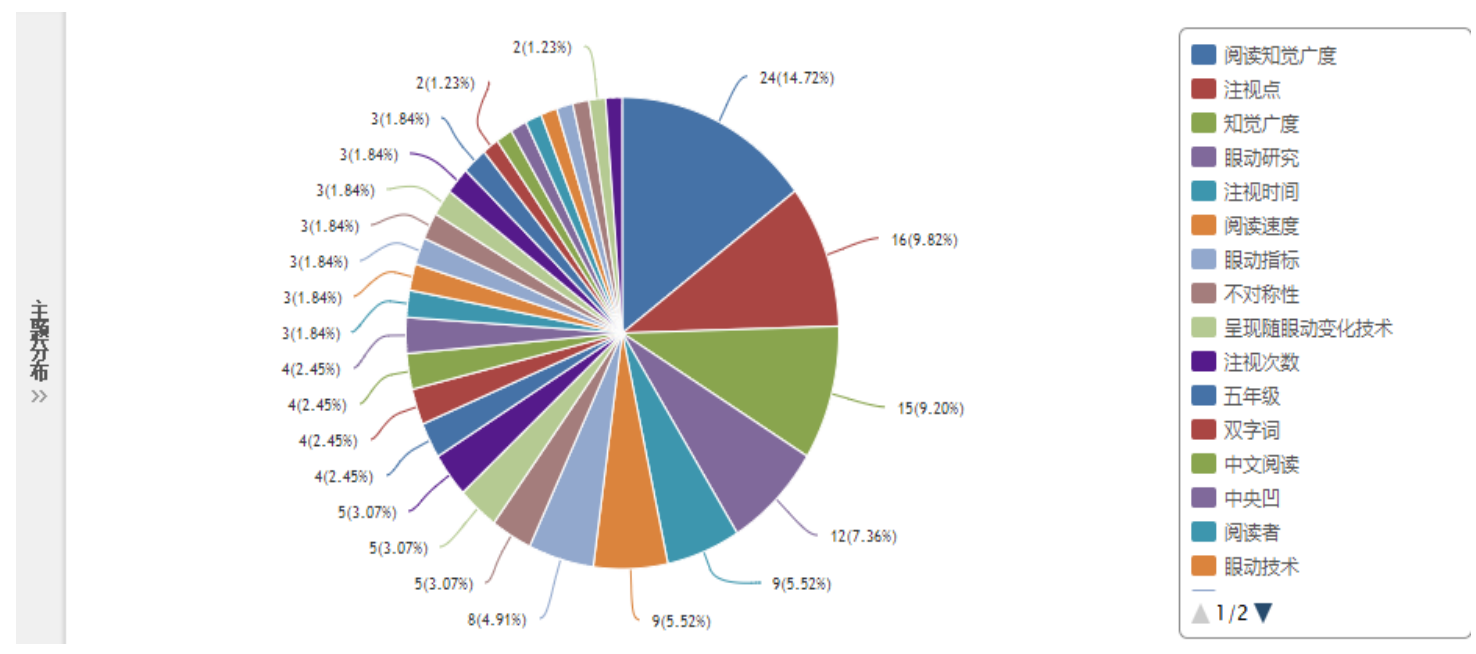

Fig. 7. Themes distribution in perceptual span studies from 1998 to 2018

1. reading perceptual span

2. fixation point

3. perceptual span

4. eye movement

5. fixation time

6. reading speed
7. eye movement index

8. asymmetry

9.eye-movement contingent display changes technique 10. fixation count

11. fifth grade

12. two-word characters

Wang Lihong studied the perceptual span of Chinese reading by using foveamasking paradigm and moving window paradigm, finding that Chinese readers read texts based on two-word characters instead of one-word characters. (.L.H.Wang, 2011)

\subsection{Perceptual span in minority language reading}

China is a multi-ethnic country. Many minorities have their own language and writing language. Therefore, the studies on perceptual span in minority language reading has become a new direction in the study of eye movements in recent years.

Some people made use of moving window paradigm, designing 7 windows $(5,9,13,17,21,25$, whole line) to study the Tibetan undergraduates' perceptual span in reading Tibetan language. Comparing the indexes of mean fixation time, fixation count, total fixation time, reading speed and rightward saccade amplitude, the study concluded that Tibetan undergraduates' perceptual span was about 4 to 8 characters of space on the right side of fixation point. ( X. J. Bai, X. L. Gao, L. Gao and Y. S. Wang, 2007)

Yao Jingyuan did research on Uygur college students' perceptual span in Chinese reading, 
finding that their perceptual span is lift- right asymmetrical and they read Chinese based on term instead of one-word character. (J.Y.Yao, 2012)

Li Weiwei compared Uygur college students' perceptual spans in Uygur reading and English reading. The study concludes two experiments: 21 Uygur college students' perceptual span in Uygur reading and 18 Uygur college students' perceptual span in English reading. Comparing the indexes of fixation count, reading time, reading speed, leftward/rightward saccade amplitude, the study found that the perceptual span in Uygur reading was about 8 to 12 characters of space on the left side of fixation point, while in English reading was about 5 to 6 characters of space on the right side of fixation point. (W.W.Li, 2013)

Doctor Gao studied Tibetan college students' perceptual span in Tibetan reading, finding that Tibetan students' perceptual span had speciality: it was about 4 to 8 characters of space on the right side of fixation point, and with the growth of age, the perceptual span exhibited the " $U$ " trend. (X.L.Gao, 2017)

\subsection{Perceptual span in English reading}

Researchers in western countries have done a lot on perceptual span in English reading. In China, researcher try to find some new points. Yan Guoli took advantage of moving window paradigm to study Chinese college students' perceptual span in English reading, finding that the perceptual span was about 8 characters of space on the right side of fixation point. (G.L.Yan, L.L. Zhang and R.Lang, 2008)

\subsection{Review on perceptual span}

Reviews are important for readers to have general knowledge of a specific field. In China, though the studies on perceptual span started late, there appeared a few distinguished researchers in the field. They summarized and classified paradigms used in Perceptual span. For example, Yan Guoli categorizes the measuring methods of perceptual span into two types: early methods and eye-movement contingent display changes technique which include moving window paradigm, moving mask paradigm and boundary paradigm. He summarized the factors affecting perceptual span and pointed out some problems to be solved in the field. All of these play important guiding roles.

\section{Conclusion}

Though in China, there have been many studies in the field, there are still many problems to be solved and studied. For one thing, in China the institutes doing research in the field are not enough. For another thing, in the field most studies are done on Chinese reading in China.

However, looking back to all the papers published in the past years, it can be found that half of them were results of the National Natural Science Fund and the National Social Science Fund, as is shown in Fig. 8. There are still many untouched studies in the field in China, for example, the comparison of perceptual span in minority's language reading (Arabic reading, Russian reading and so on). Studies in the field have great potentials in the future.

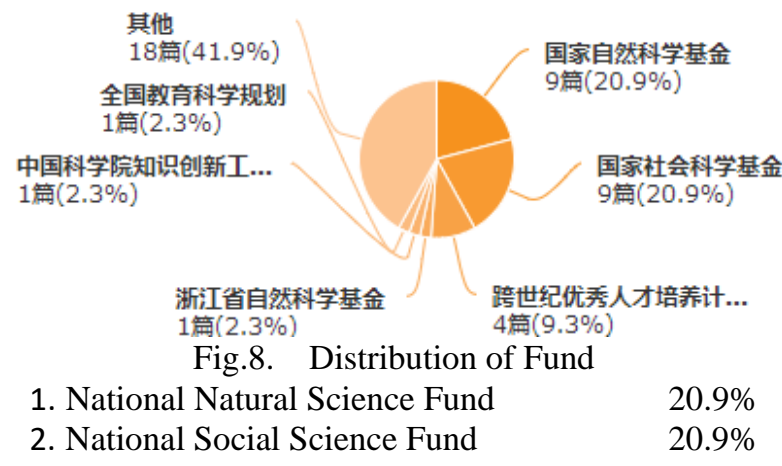




\section{Remarks:}

All the searched texts are in Chinese, so the figures are in Chinese. The words under or beside the figures are English translation.

\section{References}

[1] G.W. McConkie and K. Rayner, The span of the effective stimulus during a fixation in reading, Perception \& Psychophysics, vol.17, pp. 578-586, 1975.

[2] A.W. Inhoff and W. Liu, The perceptual span and oculomotor activity during the reading of Chinese sentences, Journal of Experimental Psychology: Human Perception and Performance,vol.24, pp 20-34.1998

[3] D.L. Peng, L.N .Orchardand J.A. Stern, Evaluation of eye movement variables of Chinese and American readers, Pavlovian Journal of Biological Science, vol.18,pp.94-102,1983.

[4] K. Rayner and J. H. Bertera, Reading without fovea. Science, vol.206, pp.468-469,1979.

[5] F. Sun, M. Morita and L. W. Stark, Comparative patterns of reading eye movement in Chinese and English, Perception and Psychophysics, vol.37, pp. 502-506,1985.

[6] X. J. Bai, X .L. Gao and Y. S. Wang, An Eye Movement Study on the Perceptual Span in Reading Tibetan Language, Acta Psychological Sinica, vol. 49, pp. 569-576, 2017.

[7] G. Fu and G. L.Yan,, The Perceptual Span and Eye Movements in Chinese Senior High School Readers, Studies of Psychology and Behavior, vol. 4, pp. 285-290, 2008.

[8] X. L.Gao, An Eye Movement Study on the Perceptual Span in Reading Tibetan Language, Doctor dissertation in Tianjin Normal University, 2017.

[9] W. W. L, The Perceptual Span of Uygur Undergraduates in Reading Uygur and English: An Eye Movement Study, Master dissertation in Tianjin Normal University, 2013.

[10]Q. Liu and S. F. Wang, A Review on Eye Movement Research of the Current Reading Perceptual Span.Journal of HUBEI Correspondence University, vol. 28, pp. 133-134, 2015.

[11]Y. H. Hong and G. L.Yan, The research theory and practical thoughts on middle school students' fast reading, Journal of Psychological Science, vol. 6, pp. 1125-1126, 2003.

[12]J. Wu, L. L. Zhang and J. G. Wu, The Perceptual Span of High School Students in Reading English, Psychological Exploration, vol. 30 pp. 29-34, 2010.

[13]J. G.Wu, G. L. Yan and Z. F. Liu, The Effect of Font Size on the Perceptual Span and Eye Movements in Chinese Reading, Journal of Psychological Science, vol.37, pp. 10-15, 2014.

[14]L. H. Wang, Eye Movement Studies on the Perceptual Span in Reading Chinese, Doctor dissertation in Tianjin Normal University, 2011.

[15]L. H. Wang, X. J. Bai and G. L. Yan, An Aging Study on the Perceptual Span in Reading Chinese: Evidence from Eye Movements, Studies of Psychology and Behavior, vol.12, pp. 763-768, 2014.

[16]J. P. Xiong, G. L. Yan and X. J. Ba, The Perceptual Span and Eye Movements in Chinese Senior High School Readers, Psychological Development and Education, vol. 5, pp. 60-64, 2007.

[17]J. P. Xiong, The Eye Movements and Perceptual Spans of Different Grades in Chinese Reading, Doctor dissertation in Tianjin Normal University, 2007.

[18]J. P. Xiong, G. L.Yan and X .J. Bai, The Eye Movements and Perceptual Spans of Different Grades in Chinese Reading, Journal of Psychological Science, vol. 32, pp. 584-587, 2009.

[19]G. L. Yan, J. G. Wu and Y. W. Hu and X. J. Bai, Review of Eye Movement Research Paradigms 
in Reading, Advances in Psychological Science, vol. 18, pp. 1966-1976, 2010.

[20]G. L. Yan, J. G. Wu, C. L. Zang and X. J. Bai, A Review of Eye-Movement Studies on Perceptual Span. Psychological Exploration, vol.30, pp. 23-28, 2010.

[21]G. L. Yan, L. L. Zhang and R. Lang, The Perceptual Span of Chinese Undergraduates in Reading English, Psychological Research, vol. 1, pp. 80-85, 2008.

[22]G. L.Yan, G. Fu and X. J. Bai, The Perceptual Span and Eye Movements in Reading Chinese Materials of Different Degrees of Difficulty, Journal of Psychological Science, vol. 31, pp. 1287-1290, 2008.

[23]G. L. Yan, J. P. Xiong and X. J. Bai, Eye Movement Studies on the Perceptual Span of Chinese Reading by Fifth Grades, Psychological Development and Education, vol. 24, pp. 72-77, 2008.

[24]J. Y. Yao, Eye Movements and the Perceptual Span in Chinese Reading of Uygur College Students, Master dissertation in Xinjiang Normal University, 2012. 